\title{
Funding big neuroscience
}

\author{
The BRAIN initiative is set to award its first grants this year. It is imperative that this initiative be funded appropriately \\ for neuroscientists to fully reap its benefits.
}

I n 2013, nearly a decade after the completion of the Human Genome project (HGP), the US government announced a provocative project that captured the attention of neuroscientists worldwide. With a mandate of developing a host of tools to study brain activity, the BRAIN initiative (Brain Research through Advancing Innovative Neurotechnologies) is expected to start evaluating its first grants early this year. Although its aims are still being worked out, the project promises to bring about important scientific and technological breakthroughs. However, if the BRAIN initiative is to be able to deliver on its promises, it will have to be funded appropriately. Unfortunately, the project is in danger of being stymied by the severe research cuts that are currently crippling all of the federal research agencies, and it is unclear how this project will be supported in the long term. It would be extremely shortsighted to curtail funding for this initiative midway or to support this project by restricting funding of other research programs. It is imperative that neuroscientists speak out in support of this project and lobby politicians to commit to this program for the longer term to ensure that the BRAIN initiative will truly be a new investment in neuroscience.

Public and private contributors have already committed $\$ 110$ million and $\$ 123$ million, respectively, for 2014. This initial investment seems impressive, but this perception could be deceiving. Because of the introduction of the US budget sequester in 2013-a series of automatic cuts on federal spending through to 2021-the US National Institutes of Health (NIH) saw a 5.5\% reduction in its 2013 budget, a $\$ 1.5$ billion loss over 2012, resulting in fewer grants being awarded and cuts to existing programs. It seems unlikely that the situation will change dramatically in the near term, raising the question as to how this project will be funded in the future. The NIH has assured neuroscientists that its initial \$40 million investment in the BRAIN initiative in 2014 will be taken out of discretionary funds that are earmarked for special projects and that it will only represent a small percentage of the $\sim \$ 5$ billion it will allocate to neuroscience research this year. Although this is a reasonable argument, it is unclear what will happen after that, when the BRAIN initiative gathers momentum and requires a steadily increasing amount of funds.

The closest recent parallel to the BRAIN Initiative is perhaps the HGP, and the financial lessons learned from this project are quite revealing. Similar to the BRAIN initiative, the HGP was a sizable, long-term, basic science project that relied on and promoted the development of new technologies. When it was launched in 1990, the HGP received $\sim \$ 87$ million in federal funds. Adjusted for inflation, this represented an initial $\sim 155$ million investment. By 2000 , the NIH was investing more than $1.5 \%$ of its total budget and the combined cost of the project in the US during that year alone was

close to half a billion dollars (in 2013 dollars). Putting a price tag on the BRAIN initiative is an exercise in speculation, but if the HGP has any predictive value, it would not be unreasonable to expect a budget rising to several hundreds of millions of dollars per year in the next few years. Unlike the HGP, however, the BRAIN initiative is developing in an inhospitable funding climate. Over the course of the HGP, the $\mathrm{NIH}$ budget nearly quadrupled, with an average yearly increase of more than $9 \%$. In comparison, since 2003, when the HGP officially ended, the NIH budget has increased by only 13\%, suffered a $5.5 \%$ decrease between 2012 and 2013 and essentially reached a stand-still 4 years ago. Although this grave deceleration of government spending on research reflects both the weakening economy and an attempt to control the federal budget deficit, it is also indicative of a general failure of American politicians to recognize that public funding of scientific research is a strategic investment in the economic strength and the well-being of the nation.

Given the unpromising state of public research funding, one could argue that it is not the right time to launch such a large and ambitious research program. This would be a mistake. The goals of the BRAIN initiative are still nebulous, but it seems very likely that the project will conceive and produce the next generation of tools to study brain structure and function and will facilitate the development of analytical tools and databases to mine and manage the wealth of neuroscience data that ensues. Ultimately, the initiative may produce a tremendous amount of new information and bring the field closer to asking more sophisticated questions. Thus, despite the current unknowns, it would be a grave mistake to not seize the opportunity and support the project.

It is therefore imperative to secure the funds that will be needed to actually see the BRAIN initiative to its completion; announcing a grand initiative only to curtail or abandon it mid-way will have devastating consequences on both science and the scientists embarking on this project. Inadequate funding would also serve to further erode the public trust in government-funded science, making the possibility of engaging in such endeavors in the future nearly impossible. It is equally important that the initiative thrive on newly created monies rather than through the recycling of funds from an already stagnant public research budget; traditional small-scale science may be necessary to eventually transform the initiative's output into fundamental neuroscience advances. To achieve these two goals, it is critical that scientists, whether they are the likely direct beneficiaries of the BRAIN initiative or not, speak out in favor of this project and convince their politicians that they need to truly put their money where their mouth is. Not doing so is only going to ensure that we erode public trust in science and further hobble US research. 